\title{
Customers' reactions to different organizational tactics in a service termination context
}

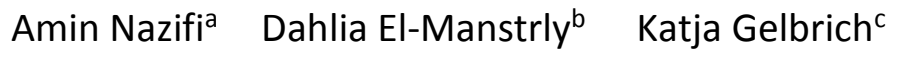 \\ anniversity of Strathclyde $\quad$ bUniversity of Edinburgh $\quad$ 'University of Eishstätt-Ingolstadt
}

\begin{abstract}
Purpose - This research examines the effects of organizational tactics (e.g., explanation and monetary compensation) on customers' reactions to service termination. The mediating role of anger and the moderating role of termination strategy on the effectiveness of organizational tactics are examined to enhance our understanding of customers' reactions to service termination.
\end{abstract}

Design/methodology/approach - Three experimental studies are conducted with different contexts (telecom, banking) and samples (students, consumers).

Findings - Study 1 results show that explanation and high monetary compensation reduce negative word of mouth (nWOM) and enhance corporate image and anger mediates these effects. Study $2 \mathrm{a}$ results show that high monetary compensation becomes ineffective when firms use a soft termination approach. Study $2 b$ results show that an explanation is equally effective in soft and hard termination approaches. Importantly, unlike high monetary compensation, explanation can fully eliminate the negative consequences of service termination.

Practical implications - Managers can mitigate negative customers' reactions to service termination by offering a truthful explanation. Further, they should provide high monetary compensation only if they do not help dismissed customers find an alternative provider.

Originality/value - This paper contributes to the service termination literature by shedding more light on the effectiveness of different organizational tactics following different termination strategies. The findings challenge existing wisdom on the overrated role of monetary compensation showing that in service termination, explanation is the most effective remedy. Further, unlike justice, anger fully explains customers' reactions to service termination. 
Keywords: Service Termination, Monetary Compensation, Explanation, Anger, Negative Word of Mouth, Corporate Image.

Article Classification: Research paper.

\section{Customers' Reactions to Different Organizational Tactics in a Service}

\section{Termination Context}

\section{Introduction}

Stories about unilateral termination of customer relationships have received considerable media coverage indicating it is a pressing phenomenon ${ }^{1}$. For example, a customer received a letter from his bank stating "We are sorry that we cannot continue our relationship with you." The letter filled the man with rage as he had remained loyal to his bank for 45 years and then, they dumped him in an ice-cold way (Freiberger, 2017).

Although firm-initiated service termination resembles a service failure in that both cause inconvenience to customers (Mattila, 2001), these differ in two important ways. First, a firm-initiated service termination often represents a strategic move (Haenlein \& Kaplan, 2009), which can affect many customers, and hence cause strong negative reactions (Albrecht, Walsh, $\&$ Beatty, 2016). Second, service termination, which is a form of selective de-marketing (Kotler \& Levy, 1971), is a deliberate act. Unlike typical service failures such as flight delays or overcooked meals, which are not intentional, terminating customer relationships results from a thought-out process. These intentional transgressions may be less frequent, but are more damaging than unintentional ones (Varela-Neira, Vázquez-Casielles, \& Iglesias, 2014).

\footnotetext{
${ }^{1}$ For a list of selected termination cases, see Table A 1. in the Online Appendix
} 
In light of these two differences, negative customers' reactions to firm-initiated service termination are likely to be stronger. In particular, affected customers often feel angry (Mittal, Sarkees, \& Murshed, 2008) and tend to retaliate, for example through negative word-of-mouth (nWOM) (Haenlein \& Kaplan, 2010; Lepthien, Papies, Clement, \& Melnyk, 2017). As a typical revenge-seeking behavior (Grégoire, Laufer, \& Tripp, 2010), nWOM can cause further problems to firms. This is particularly true at an age where, thanks to social media, such reactions can become viral and cause public uproar (Haenlein \& Kaplan, 2012). Service termination can also damage firms' image (Alajoutsijärvi, Möller, \& Tähtinen, 2000) and impose significant indirect costs such as the loss of other existing customers and the negative impact on future acquisition (Haenlein \& Kaplan, 2010). Interestingly, the negative reactions of other existing customers towards termination is also quite high, irrespective of the tie strength with the affected customers (Haenlein \& Kaplan, 2012).

Given these detrimental effects, it is important that firms reduce customers' anger and nWOM and restore their image through appropriate organizational tactics. In our introductory example, the bank only felt "sorry" for terminating the old man's account. In other cases, Amex offered customers $\$ 300$ (Fournier, Breazeale, \& Fetscherin, 2012), whereas TCF bank closed customers' accounts without any compensation or explanation (Dave, 2014).

Academic research on effectiveness of organizational tactics on customers' reactions to service termination is limited. Among a few studies, Lepthien et al. (2017) found that high monetary compensation or offering a downgrade as an alternative to termination can reduce customers' negative reactions. Further, Haenlein and Kaplan (2010) investigated the effectiveness of offering products with a better value (i.e., better quality or lower prices) to improve the firm's image among other customers. However, this was only effective among other existing customers, but not among prospective customers, indicating that termination can significantly hurt future acquisition. 
Yet, three important issues remain unexplored. First, the effectiveness of psychological compensation, which is considered a salient remedy in prior research on firms' transgressions (Davidow, 2003; Roschk \& Gelbrich, 2014), has not been examined in a service termination context yet. As psychological compensation, we argue that an explanation, rather than an apology, is necessary. This is because customers need to understand why firms deliberately take such a hostile action.

Second, there is a lack of research on examining the interplay between different organizational tactics, such as monetary compensation or explanation, and different termination strategies (Alajoutsijärvi et al., 2000). Specifically, Grewal, Roggeveen, and Tsiros (2008) call for research on the boundary conditions for the effectiveness of compensation. It is conceivable that a soft termination (i.e., offering to move customers to another provider) as opposed to a hard termination (i.e., terminating the relationship without offering an alternative provider) strategy may render specific organizational tactics unnecessary.

Third, there is a lack of research on customers' emotional reactions to termination (Haenlein \& Kaplan, 2012). Lepthien et al. (2017) present injustice or unfairness as a cognitive mediator, defined as the perception that service termination contradicts the treatment customers are entitled to, yielding negative customer behavior. Drawing on cognitive appraisal theory, which claims that people evaluate an event based on several dimensions, including desirability and agency (comprising self vs. other agency, controllability and intentionality) (Watson \& Spence, 2007; Weber, 2004), we argue that a firm-initiated service termination is an undesirable and intentional act caused and controlled by the firm and thus, tends to trigger strong emotional reactions like anger (Mittal et al., 2008). In support, Nguyen and McCollKennedy (2003) argue that an unfair treatment, being an undesirable event, may elicit negative emotional reactions, ranging from less intense emotions such as dissatisfaction (Bougie, Pieters, \& Zeelenberg, 2003) to more intense emotions such as anger (Mikula, Scherer, \& 
Athenstaedt, 1998). Accordingly, injustice perception may precede anger following a transgression, but anger is only provoked when a firm is perceived as responsible and causing the harm on purpose (De Cremer, Wubben, \& Brebels, 2008). Prior research shows that when anger is elicited, it can fully mediate the effect of (in)justice on misbehavior (Beijersbergen, Dirkzwager, Eichelsheim, Van der Laan, \& Nieuwbeerta, 2015; Murphy \& Tyler, 2008). Given that anger, as a specific attribution-dependent emotion that fosters customer revenge and nWOM (Tripp, Bies, \& Aquino, 2007), taps into a more refined cognitive process of blaming a transgressor (Nguyen \& McColl-Kennedy, 2003; Watson \& Spence, 2007), it may ultimately drive customers' reactions to severe and intentional firm transgressions such as service termination.

In sum, we aim to answer three questions: 1 . How effective are different organizational tactics in reducing customers' negative reactions to service termination? 2. Does service termination strategy moderate the effects of these organizational tactics? 3. Does anger rather than justice fully explain these relationships? Answering these questions makes three contributions to the service termination literature.

First, we examine the remedial effect of monetary compensation and its boundary condition on customer nWOM and image perceptions after service termination. Building on Lepthien et al. (2017), we present high monetary compensation (as a seemingly powerful organizational tactic) in a different light and show that service termination strategy moderates its effect. Specifically, while high monetary compensation is effective with a hard termination, it can be rendered unnecessary with a soft termination approach. Second, we show that explanation (first time examined in a service termination context) is more powerful than money (at least with respect to $\mathrm{nWOM}$ ) and its effect is robust, that is, independent of the termination strategy. This is important because explanation is a cost-free alternative to monetary compensation. Further, apology, does not help with an intentional act like customer dismissal. 
Third, we show that anger (as a specific attribution dependent emotion) is decisive for assessing the effectiveness of organizational tactics on customers' reactions to service termination, while justice no longer plays a key role. These findings provide managers with critical insights on how to handle service termination in a way that minimizes the negative consequences for the focal firm. Given that reducing anger is the key to minimizing negative customers' reactions, our recommendations center around mitigating perceived firm-agency of the termination act. This effect can be best achieved by providing a truthful explanation for dismissing customers, regardless of the chosen termination strategy. Another way to reduce anger is offering to move customers to alternative providers. This soft termination approach offers a way to avoid high investment into monetary recompense, which, otherwise, may be necessary with a hard termination approach.

\section{Theoretical foundations}

\section{Cognitive Appraisal Theory}

Our theoretical framework is based on cognitive appraisal theory (Ortony \& Clore, 1988), which offers a deeper understanding of how emotions occur. The theory predicts what emotions are provoked following an event and how these emotions influence behavioral responses (Watson \& Spence, 2007). The first core proposition is that people evaluate a situation on different appraisal dimensions. The primary dimension is outcome desirability, which refers to whether the outcome of a situation is desirable (positive) or undesirable (negative). As such, it determines the valence of an emotion (Ruth, Brunel, \& Otnes, 2002). The next important appraisal dimension is agency (Ortony \& Clore, 1988), which is derived from causal attribution theory (Watson \& Spence, 2007), and includes the agent (i.e., internal vs. external), perceived 
control (i.e., controllable vs. uncontrollable) and intentionality ${ }^{2}$ (i.e., intentional vs. unintentional). Agency can be attributed to oneself (i.e., internal) which can lead to guilt, to others (i.e., external) which can cause anger, or to a circumstance which can result in frustration, but only the first two are perceived to be controllable (Watson \& Spence, 2007). As such, anger can be defined as an emotion that occurs when an intentional event with an undesirable outcome is attributed to someone else as responsible for the problem (De Cremer et al., 2008).

The second core proposition of appraisal theory is that specific emotions tend to trigger certain behavioral reactions (Frijda, Kuipers, \& Ter Schure, 1989). Angry people, for example, often try to attack the person responsible for a harmful situation (Lazarus, 1991). We transfer these notions to service termination, which represents a "violation of implicitly assumed social norms" (Haenlein \& Kaplan, 2011, p. 85). It is a deliberate firm action with negative consequences for the customers who may feel denigrated and have to find an alternative provider (Mittal et al., 2008). As such, an undesirable and deliberate act caused by the firm, induces anger and negative customers' reactions such as nWOM (Haenlein \& Kaplan, 2012) and image loss (Alajoutsijärvi et al., 2000).

Hence, organizational tactics aimed to mitigate these customers' reactions have to reduce the preceding anger. Here, appraisal theory suggests that the firm could seek to influence customer appraisal on the two dimensions comprised in anger. Specifically, they could reduce the outcome undesirability (by mitigating the negative consequences of service termination) or firm-agency (by reducing perceptions that the firm is responsible for service termination and intends to harm the customer).

\footnotetext{
${ }^{2}$ While controllability and intentionality are sometimes used interchangeably, these two are distinct constructs which can determine whether a harm is done on purpose or due to negligence (e.g., see Varela-Neira et al., 2014).
} 
In the following, we will build on this idea when hypothesizing the effectiveness of the different organizational tactics — monetary compensation and explanation- in service termination. In our conceptual framework, presented in Figure 1, we propose that high, but not low, monetary compensation (H1) and explanation (H2) mitigate anger, reducing nWOM (a) and fostering firm image (b). Further, we propose that service termination strategy (hard vs. soft termination) moderates the effects of high monetary compensation (H3) and explanation (H4) on nWOM (a) and image (b).

Figure 1 to be inserted here

\section{Hypotheses on the effects of organizational tactics}

Monetary compensation. Monetary compensation consists of financial remuneration such as refund or cash-equivalent offered to customers who encounter a service problem (BambauerSachse \& Rabeson, 2015). The remedial effect of monetary compensation for service failures is well-established, resulting in reduced anger (Chebat, Davidow, \& Codjovi, 2005; Walster, Berscheid, \& Walster, 1973) and nWOM (Coombs \& Holladay, 2008) as well as enhancing corporate image (Benoit \& Drew, 1997).

In a service termination context, we argue that dismissed customers need to invest time and effort, which is considered an economic loss (Bagozzi, 1975). Based on cognitive appraisal theory, monetary compensation should be an appropriate tactic as it can reduce the undesirability of the outcome. This is because following a negative incident that is caused by someone else, customers feel angry and seek redress (Nguyen \& McColl-Kennedy, 2003). Hence, offering monetary compensation for the inconveniences caused by service termination can reduce the undesirability of the outcome (i.e., the negative valence), reducing anger (Chebat \& Slusarczyk, 2005) and subsequent negative reactions. 
Prior research supports that the amount of monetary compensation should be consistent with the intensity of the negative encounter (Smith, Bolton, \& Wagner, 1999), because a mismatch can even increase anger (Walster et al., 1973). This means for a minor problem, low compensation is required and for a severe problem, high compensation is needed. Indeed, Bambauer-Sachse and Rabeson (2015) find that higher monetary compensation is more effective in more severe service problems, which is consistent with Balaji and Sarkar (2013)'s suggestion that compensation strategy should be designed according to the magnitude of problem. Accordingly, in case of service termination — which is a severe problem- high monetary compensation would be needed to diffuse customers' anger and their subsequent negative reactions.

Lepthien et al. (2017) provide initial support for our arguments, showing that only substantial (but not small) compensation amounts decrease dismissed customers' unfairness perceptions. They also suggest, but do not test, that high monetary compensation can reduce customers' negative emotions. Accordingly, we consider offering no compensation as a baseline and hypothesize that high, but not low monetary compensation can reduce the undesirability of the termination, resulting in lower nWOM and higher firm image perception, and these relationships are mediated by anger. Formally:

H1a: High monetary compensation decreases nWOM following service termination, mediated by anger.

H1b: High monetary compensation increases corporate image following service termination, mediated by anger.

Explanation. Explanation means to provide "the reason for, or the cause of, some event that is not immediately obvious or entirely known" (Shaw, Wild, \& Colquitt, 2003, p. 445). In the context at hand, it means informing customers why they were dismissed. Prior research 
indicates that an explanation is only effective if it is perceived as truthful and reasonable (Colquitt, 2001). Offering an appropriate explanation to customers at times of negative service encounters can reduce customers' anger and nWOM (Gelbrich, 2010), while lack of an appropriate explanation can make customers angry (Wang \& Mattila, 2011).

Drawing on cognitive appraisal theory, an explanation can shed light on the causal attribution dimension and help customers re-assess the perceived agency for the service termination. According to Nguyen and McColl-Kennedy (2003), displacing the responsibility away from the provider mitigates customers' anger. For example, in a termination context, offering an explanation can reduce firm-agency by informing customers that they are partly responsible, for instance due to excessive complaint (Haenlein \& Kaplan, 2012) or lack of profitability (Mittal et al., 2008). In diverting the blame away from the firm, customers may feel less angry, which in turn, tends to reduce their negative reactions to the firm's transgressions (Chebat \& Slusarczyk, 2005; Gelbrich, 2010). Formally, we hypothesize that, compared to no explanation:

H2a: Explanation decreases nWOM following service termination, mediated by anger.

$\mathrm{H} 2 \mathrm{~b}$ : Explanation increases corporate image following service termination, mediated by anger.

Another organizational tactic, which effectively mitigates anger after firms' transgressions, is apology (Nguyen \& McColl-Kennedy, 2003). This is because an apology comprises expressions of remorse and thus, acknowledges blame for the negative event (Roschk \& Kaiser, 2013). Yet, deliberately closing a customer's account and-at the same time-apologizing for this action could be perceived as insincere. Given that perceived sincerity is a precondition for an apology to be effective (Roschk \& Kaiser, 2013), we expect a null effect of apology tactic in a service termination context. 


\section{Hypotheses on moderating effects of termination strategy}

Firms can use a hard approach or a soft approach to terminate customer relationships (Haenlein, Kaplan, \& Schoder, 2006). In the hard approach, firms focus on short-term self-interest by explicitly telling customers the relationship has come to an end with no opportunity for negotiation (Alajoutsijärvi et al., 2000). In the soft approach, firms wish to end the relationship amicably by offering to move customers to another provider (Mittal et al., 2008).

Drawing on cognitive appraisal theory, hard termination should be perceived as more undesirable because customers would have to invest time and effort to find an alternative provider. Further, uncertainty about the future can reinforce negative emotions (Watson \& Spence, 2007). Here, not knowing whether other companies can provide the required service or how long it will take to resume the service are unknowns that can create uncertainty. This uncertainty may increase the undesirability of a hard termination approach and result in higher anger. Grégoire et al. (2010) support this notion that a more severe problem can reinforce anger.

Hence, a higher redress may be needed to reduce these high anger levels. Indeed, Smith et al. (1999) show that compensation is more effective in a severe problem compared with a minor problem. Roggeveen, Tsiros, and Grewal (2012) also report that offering compensation will lead to more favorable responses after a severe (vs. minor) problem. Likewise, Van Vaerenbergh, Larivière, and Vermeir (2012) show that customers who experience negative encounters with greater magnitude are likely to react more favorably toward organizational compensation tactics. Therefore, offering high monetary compensation is necessary following a hard termination approach.

Following a soft termination, the customer still has the option to be transferred to another provider without any hassle (Mittal et al., 2008) and hence can avoid service disruption. Similarly, Lepthien et al. (2017) suggest that offering an alternative service rather than termination may reduce negative emotions. Accordingly, a soft termination strategy can be 
perceived as a less undesirable outcome, which can lead to lower anger and negative customers' reactions. Therefore, high monetary compensation is not necessary following soft termination. Formally, we hypothesize that the anger-reducing effects of high monetary compensation are stronger for a hard (vs. soft) termination approach:

H3a: The mediating effect of high monetary compensation on nWOM through anger is moderated by termination strategy, such that the effect is more pronounced for a hard (vs. soft) termination strategy.

H3b: The mediating effect of high monetary compensation on corporate image through anger is moderated by termination strategy, such that the effect is more pronounced for a hard (vs. soft) termination strategy.

We also propose an anger-reducing effect when combining an explanation with a hard termination approach, but this effect may work through decreasing firm-agency. Firms adopting a hard termination approach focus on self-interest and lack concern for the customers (Alajoutsijärvi et al., 2000). This can further reinforce customers' evaluations that the firm is responsible for this problem, increasing anger and negative reactions. Offering an explanation may enable customers to see the problem from the firm's perspective and re-evaluate their blame attribution, which can subsequently reduce anger after a hard termination. Indeed, prior research supports that firms which successfully shift the blame away from themselves through explanation can diffuse customers' anger (Nguyen \& McColl-Kennedy, 2003).

In contrast, following a soft termination approach, the firm takes responsibility by showing the willingness to go the extra mile to help the customer with a smoother transition (Mittal et al., 2008). Therefore, the perceived firm-agency may be weaker. Based on cognitive 
appraisal theory, this can lead to lower anger and negative reactions and hence, offering an explanation would not be necessary. Thus, we hypothesize:

H4a: The mediating effect of explanation on $\mathrm{nWOM}$ through anger is moderated by termination strategy, such that the effect is more pronounced for a hard (vs. soft) termination strategy.

$\mathrm{H} 4 \mathrm{~b}$ : The mediating effect of explanation on corporate image through anger is moderated by termination strategy, such that the effect is more pronounced for a hard (vs. soft) termination strategy.

\section{Overview of studies}

Three experimental studies examine the effects of different organizational tactics on customers' reactions to service termination, the process at work, and potential boundary conditions. Study 1 draws on a telecom setting and a student sample. It tests the effects of monetary compensation $(\mathrm{H} 1 \mathrm{a}, \mathrm{b})$ and explanation $(\mathrm{H} 2 \mathrm{a}, \mathrm{b})$ on nWOM and corporate image, through the mediating role of anger. The two subsequent studies test whether service termination strategy moderates the processes "organizational tactic $\rightarrow$ anger $\rightarrow$ nWOM, image." Study 2a focuses on monetary compensation (H3a, b) and Study $2 \mathrm{~b}$ focuses on explanation $(\mathrm{H} 4 \mathrm{a}, \mathrm{b})$.

\section{Study 1}

Purpose

Study 1 tests whether high (but not low) monetary compensation (H1) and explanation (H2) decrease nWOM (a) and increase corporate image (b), mediated by anger. Though not specifically hypothesized, we also test the proposed null-effect of apology. 
We conducted a scenario-based, single factor experiment, manipulating organizational tactics with five conditions (low monetary compensation, high monetary compensation, explanation, apology, and a control group with no compensation) (see Online Appendix A 3. for the scenarios). We chose home broadband services, which was deemed appropriate for undergraduate students recruited from a business school in Western Europe. They were invited to complete a pen and paper questionnaire in exchange for charity donations. Excluding incomplete answers $(n=5)$ yielded 114 respondents (female: 57\%; younger than 24 years: 97.4\%). Participants were randomly assigned to one of the five scenarios.

\section{Manipulations}

The core scenario describes a letter from a broadband provider communicating that following a recent review of the account, the company has decided to withdraw its services and is giving 30 days' notice to terminate the account. Next, the customer contacts the customer service to complain and is or is not offered monetary compensation, an explanation, or an apology. In a pretest with university students $(n=38)$, the average amount of monetary compensation expected following termination of their broadband account was $£ 100$. We added/subtracted an equal amount (£50) to determine our high $(£ 150)$ and low (£50) compensation. The success of this manipulation was checked in the main study (see below).

\section{Measures}

After reading the scenario, participants answered questions on nWOM adapted from Bougie, Pieters, and Zeelenberg (2003) $(\alpha=.97)$, corporate image adapted from Mostafa et al. (2015) $(\alpha=.98)$, and anger taken from Grégoire and Fisher (2008) and Bougie et al. (2003) $(\alpha=.97)$, all measured with three items (see Table A 2. in the Online Appendix). As control variables, attitude towards complaining (ATC) was measured according to Roschk and Gelbrich (2014) 
(three items; $\alpha=.86$ ), attributions based on Gelbrich, Gäthke, and Grégoire (2015) (three items; $\alpha=.74$ ) and perceived severity (three items, $\alpha=.92$ ) and service importance ( 1 item) based on Hess, Ganesan, and Klein (2003). This is because these variables are shown to influence customers' reactions to firms' transgressions in previous research (Grégoire et al., 2010; Hess et al., 2003). Seven-point Likert scale (1: strongly disagree to 7: strongly agree) were used, except for service importance and perceived severity (seven-point bipolar scales). We also added gender as a demographic control.

\section{Results}

Manipulation checks. Three nominal attention checks were used, testing if respondents understood that they received monetary compensation (None/£50/£150), an explanation (yes/no), and an apology (yes/no). Twenty respondents provided incorrect answers. They were excluded from further analysis (Albrecht et al., 2016), yielding a net sample size of $n=94$. The success of the manipulations was checked using 7-point Likert scales (Mostafa, Lages, Shabbir, \& Thwaites, 2015). For compensation, five items were used (e.g., I was offered an adequate monetary compensation by the company; $\alpha=.98$ ). The mean values differed significantly across compensation levels, in the desired direction $\left(\mathrm{M}_{\mathfrak{1} 150}=4.99>\mathrm{M}_{£ 50}=3.84>\mathrm{M}_{\text {Control }}=\right.$ 2.19, $\mathrm{F}[2,91]=57.36, \mathrm{p}<.001)$. For explanation, four items were used (e.g., The company explained what factors might have caused the problem; $\alpha=.97$ ), with significant differences between the two conditions $\left(\mathrm{M}_{\text {Explanation }}=5.22>\mathrm{M}_{\mathrm{No} \text { Explanation }}=2.05, \mathrm{~F}[1,92]=112.33, \mathrm{p}<\right.$ .001). Four items were used for apology (e.g., The company apologized to me for what had happened.; $\alpha=.93)$, with significant differences between the mean values $\left(\mathrm{M}_{\text {Apology }}=4.68>\right.$ $\left.\mathrm{M}_{\mathrm{No} \text { Apology }}=2.61, \mathrm{~F}[1,92]=50.25, \mathrm{p}<.001\right)$. Respondents perceived scenarios as realistic on a two-item seven-point scale (e.g., I believe that such incidents are likely to happen in real life; 
$\alpha=.92)$, with the mean value greater than the scale midpoint $(\mathrm{M}=5.29, \mathrm{t}=10.76, \mathrm{p}<.001)$, which did not differ across groups $(\mathrm{F}=1.17, \mathrm{p}<.330)$.

Direct effects of organizational tactics. Results of two ANCOVAs with the organizational tactic as the independent variable, nWOM/image as the dependent variable, and including the five controls show a significant effect of organizational tactic on $\mathrm{nWOM}(\mathrm{F}=22.78, \mathrm{p}<.001$, $\left.\eta^{2}=.52\right)$ and corporate image $\left(F=21.66, p<.001, \eta^{2}=.51\right)$. Among the control variables, service importance and attribution had significant effects on the DVs, although inclusion or exclusion of the controls did not significantly influence the results.

Effect of compensation. Post-hoc tests ${ }^{3}$ reveal that $\mathrm{nWOM}$ is significantly lower in the high monetary compensation group than in the no response control group $\left(\mathrm{M}_{\text {High compensation }}=3.99<\right.$ $\left.\mathrm{M}_{\text {Control }}=5.76, \mathrm{p}<.001\right)$, while nWOM for low monetary compensation does not differ significantly from the control group $\left(\mathrm{M}_{\text {Low compensation }}=5.07, \mathrm{p}<.057\right)$. Regarding corporate image, post-hoc comparisons indicate a higher image in the high monetary compensation group, compared to the control group $\left(\mathrm{M}_{\text {High compensation }}=4.90>\mathrm{M}_{\text {Control }}=2.57, \mathrm{p}<.001\right)$, while image for low monetary compensation is as high as in the control group $\left(\mathrm{M}_{\text {Low compensation }}=2.77\right.$, $\mathrm{p}<.598)$

Effect of explanation. Post-hoc tests show a significantly lower nWOM level for explanation, compared to the control group $\left(\mathrm{M}_{\text {Explanation }}=3.22<\mathrm{M}_{\text {Control }}=5.76, \mathrm{p}<.001\right)$. The former value is even significantly lower than in the high monetary compensation condition $\left(\mathrm{M}_{\text {Explanation }}=\right.$ $3.22<\mathrm{M}_{\text {High compensation }}=3.99, \mathrm{p}<.020$ ). For image, post-hoc tests indicate significantly higher image levels in the explanation condition than in the control condition $\left(\mathrm{M}_{\text {Explanation }}=4.90>\right.$

\footnotetext{
${ }^{3}$ We used LSD as the default test, but other tests yielded similar results.
} 
$\left.\mathrm{M}_{\text {Control }}=2.57, \mathrm{p}<.001\right)$, but the former value is not significantly higher than in the high monetary compensation condition $\left(\mathrm{M}_{\text {Explanation }}=4.90>\mathrm{M}_{\text {High compensation }}=4.49, \mathrm{p}<.223\right)$.

Effect of Apology. As expected, post-hoc tests indicate that apology does not significantly affect $n W O M(M=5.67, p=.785)$ or image $(M=2.62, p=.887)$, compared to the control group. Figure 2 depicts the results.

Figure 2 To Be Inserted Here

Test of $\mathrm{H} 1$ and $\mathrm{H} 2$. For a formal test of $\mathrm{H} 1$ and $\mathrm{H} 2$, a mediation analysis is conducted using the PROCESS tool and Model 4 (Hayes, 2013). We select organizational tactic with five categories as the independent variable, nWOM and image as the dependent variables, anger as the mediator, and include the five controls. Because the independent variable organizational tactic is multi-categorical, the first group (here: no response tactic) serves as a baseline, which is tested against the other groups (Hayes \& Preacher, 2014), these being the single organizational tactics.

High monetary compensation exerts a significant negative effect on anger $(b=-1.47, \mathrm{t}$ $=-4.24, \mathrm{p}<.001)$. Anger has a significant positive effect on $\mathrm{nWOM}(\mathrm{b}=.61, \mathrm{t}=7.19, \mathrm{p}<$ $.001)$ and a significant negative effect on image $(b=-.58, t=-6.18, p<.001)$. The indirect effects of high monetary compensation on nWOM $(b=-.89, \mathrm{SE}=.29, \mathrm{CI}:-1.51$ to -.38$)$ and image $(\mathrm{b}=.84, \mathrm{SE}=.29, \mathrm{CI}: .34$ to 1.49$)$ through anger are significant, as indicated by the 95\%-confidence intervals excluding zero, supporting H1a and H1b.

Explanation exerts a significant negative effect on anger $(\mathrm{b}=-2.17, \mathrm{t}=-6.52, \mathrm{p}<.001)$. Its indirect effects on $\mathrm{nWOM}(\mathrm{b}=-1.32, \mathrm{SE}=.26, \mathrm{CI}:-1.84$ to -.81$)$ and image $(\mathrm{b}=1.25, \mathrm{SE}$ $=.28$, CI: .74 to 1.86 ) through anger are significant, supporting $\mathrm{H} 2 \mathrm{a}$ and $\mathrm{H} 2 \mathrm{~b}$. 


\section{Ruling out alternative models}

Although not specifically hypothesized, we also examine the role of injustice, which is presented as mediating the effects of organizational tactics on customers' behavioral reactions in prior research (Lepthien et al., 2017). Anger as the mediator in our framework is an emotion resulting from cognitive evaluations of an event's undesirability and other agency (Averill, 1983). As such, injustice perceptions shaped by external attributions of an undesirable and controllable event caused by the firm on purpose (De Cremer et al., 2008; Watson \& Spence, 2007) may also precede anger (Chebat \& Slusarczyk, 2005). Indeed, justice is an important aspect of people's everyday lives (De Cremer et al., 2008) because it reassures them that they are a valued member of a society. An unfair treatment damages this perception and makes customers feel disrespected and excluded from the society, which in turn can harm their selfidentity and self-worth (Murphy \& Tyler, 2008). Anger is shown to fully mediate the effect of (in)justice on misbehavior (Beijersbergen et al., 2015). Accordingly, in a termination context, anger is a strong negative emotional reaction that may embed injustice and act as the primary driver of customers' subsequent reactions. In order to support this notion, we test an alternative model to show that when anger is present, injustice perception is no longer instrumental in explaining customers' reactions to termination.

Accordingly, we test a serial mediation model (using Hayes' Process Model 6) where perceived justice (three items taken from Smith et al. (1999), $\alpha=.94)$ precedes anger in explaining the effects of organizational tactics on nWOM and image, respectively (tactics $\rightarrow$ justice $\rightarrow$ anger $\rightarrow$ DVs).

The results of serial mediation are similar to the results using anger as the sole mediator (tactics $\rightarrow$ anger $\rightarrow$ DVs) and the explanatory power of the model for anger alone is the same as the justice-anger serial link model, but higher than justice alone model for both nWOM (R 
square of .73 rather than .61) and image (R square of .71 rather than .63). Regarding nWOM, the results show significant indirect effects of high monetary compensation $(b=-.31, \mathrm{SE}=.11$, CI: -.55 to -.10$)$ and explanation $(b=-.47, \mathrm{SE}=.15, \mathrm{CI}:-.80$ to -.20$)$ for the serial mediation link "tactics $\rightarrow$ justice $\rightarrow$ anger $\rightarrow$ nWOM". The corresponding indirect effects through anger only (tactics $\rightarrow$ anger $\rightarrow$ nWOM) are also significant and of a similar size (high monetary compensation: $\mathrm{b}=-.31, \mathrm{SE}=.17, \mathrm{CI}:-.70$ to -.02 ; explanation: $\mathrm{b}=-.45, \mathrm{SE}=.20, \mathrm{CI}:-.88$ to $.09)$, whereas the indirect effects through perceived justice "tactics $\rightarrow$ justice $\rightarrow$ nWOM" are non-significant (high monetary compensation: $\mathrm{b}=-.04, \mathrm{SE}=.09, \mathrm{CI}:-.23$ to .14 ; explanation: $\mathrm{b}=-.06, \mathrm{SE}=.14, \mathrm{CI}:-.34$ to .20$)$.

Results for image show significant indirect effects of high monetary compensation (b $=.25, \mathrm{SE}=.11, \mathrm{CI}: .07$ to .52$)$ and explanation $(\mathrm{b}=.38, \mathrm{SE}=.16, \mathrm{CI}: .14$ to .76$)$ through the justice-anger link, significant and similar indirect effects through anger (monetary compensation: $\mathrm{b}=.25, \mathrm{SE}=.14, \mathrm{CI}: .02$ to .58 ; explanation: $\mathrm{b}=.36, \mathrm{SE}=.17, \mathrm{CI}: .07$ to .73 ), but non-significant indirect effects through justice (monetary compensation: $b=.14, \mathrm{SE}=.14$, CI: -.14 to .43 ; explanation: $b=.22, \mathrm{SE}=.20, \mathrm{CI}:-.23$ to .57$)$.

\section{Discussion}

Study 1 findings show that high (but not low) monetary compensation and explanation improve customers' reactions to service termination. Counter to the popular belief (e.g., Davidow, 2003), explanation is more effective than (high) monetary compensation. As expected, an apology, is not effective in a service termination context. It does not seem to be considered as sincere, because terminating a customer account is an intentional act. Hence, apology is excluded from further examinations. Importantly, and in support of our H1a, b and H2a, b, the results show a mediating role of anger on the effects of high monetary compensation and explanation on nWOM and image. Finally, the results of our competing model analyses show 
that in a termination context, the effect of justice is diminishing when including anger and that anger, rather than justice, plays a primary role in driving customers' reactions. Therefore, we only use anger as the mediator in the subsequent studies.

\section{Study 2a}

Purpose

Study 2 a tests robustness for Study 1 results for monetary compensation in another sector (banking rather than telecom) and another sample (consumers rather than students). Importantly, it tests termination strategy (hard vs. soft) as a moderator on the process at work (H3).

\section{Design and data collection}

We conducted a scenario-based experiment with a 2 (service termination strategy: hard vs. soft) by 3 (monetary compensation: no vs. low vs. high) between-subject design, yielding six conditions. The baseline scenario described the closure of a credit card account as this type of service termination occurred most often in the consumer complaints regarding the closure of bank accounts reported to the US Consumer Financial Protection Bureau (CFPB, 2016).

Participants were recruited through Critical Mix, which is an online panel with US adult consumers. They were invited by posting the invitation to participate in this online experiment on the panel platform in exchange for a small compensation. We obtained a sample of 220 completed questionnaires (male: $52.3 \%$, younger than 45 years: $44.1 \%$, married: $50.0 \%$, at least a college degree: $63.6 \%$ ). We randomly assigned respondents to the six groups.

\section{Manipulations}


To keep a balance between control and ecological validity, we used video clips comprised of photographs and audio recordings (Bateson \& Hui, 1992). In the video clip, we showed some photos including a letter marked urgent and a fictitious termination letter that displayed the text related to the manipulation of termination strategy while a narrator read out the core scenario. The stimuli included in the letter stated that following a recent review of the account, the bank withdraws its services and is giving 60 days' notice of intention to close the credit card account.

Service termination strategy was manipulated as follows: For the hard approach, the customer is required to make alternative arrangements at another financial institution and pay off or transfer any outstanding balance by the end of the 60-day period. For the soft approach, the bank appreciates this may cause inconvenience and will make the transition smooth by offering help to move to another provider. Next, the customer contacts the bank's customer service team to complain and is or is not offered monetary compensation (see Online Appendix A 4. for scenarios).

Monetary compensation levels were determined based on two pretests with subjects similar to the main study recruited from a US consumer panel. In the first pretest $(n=55)$, the average amount of monetary compensation expected following a bank account closure was identified (i.e., $M=\$ 150$ ). Similar to Study 1 , we selected $\$ 50$ below or above the average expected amount as low (i.e., \$100) and high (i.e., \$200) monetary compensation. In a subsequent pretest $(n=71)$, we checked the manipulation of these levels using five items similar to Study 1 on a 7-point scale. The mean values differed significantly across different compensation levels, in the desired direction $\left(\mathrm{M}_{\$ 200}=5.04>\mathrm{M}_{\$ 100}=3.92>\mathrm{M}_{\text {Control }}=2.11, \mathrm{~F}\right.$ $[2,68]=40.76, \mathrm{p}<.001)$

\section{Measures}


The dependent variables were the same nWOM $(\alpha=.91)$, image $(\alpha=.96)$, and anger $(\alpha=.94)$ measures as in Study 1. We included the same controls: ATC $(\alpha=.87)$, severity $(\alpha=.89)$, attributions $(\alpha=.68)$, service importance, and gender. Attribution failed to achieve the .7 threshold for internal consistency, so we only retained one item (see Table A 2. in the Online Appendix). Given that Study 2a used consumers, we also added age as an additional control.

\section{Results}

Manipulation checks. The termination strategy manipulation was checked through a pretest (Perdue \& Summers, 1986), with 58 subjects similar to the main study recruited from a US consumer panel. The measure comprised four self-developed items (e.g., The bank showed interest in facilitating my transition to another bank; $\alpha=.92$ ). Its mean value differed significantly across strategies, in the desired direction $\left(\mathrm{M}_{\text {Hard }}=2.79 ; \mathrm{M}_{\text {Soft }}=4.27, \mathrm{~F}[1,56]=\right.$ $14.59, \mathrm{p}<.001)$

Following an attention check in the main study $(\mathrm{n}=220), 91 \%, 95 \%$, and $93 \%$ of respondents correctly identified whether they received no money, $\$ 100$, or $\$ 200$ respectively. Removing the 16 cases with incorrect answers yielded a net sample of $n=204$. These respondents perceived the scenarios as realistic (same two items as in Study $1 ; \alpha=.93$ ), with the mean value significantly higher than the scale midpoint $(\mathrm{M}=5.16, \mathrm{t}=11.71, \mathrm{p}<.001)$ and did not differ across groups $(\mathrm{F}=1.09, \mathrm{p}<.366)$. Hence, the manipulations were successful.

Overview. Hypotheses are tested conducting a moderated mediation analysis using the PROCESS tool and Model 8 (Hayes, 2013) with a multi-categorical independent variable (Hayes \& Preacher, 2014), testing the baseline group (no monetary compensation) against the other groups (high and low monetary compensation). 
Test of H3a. H3a refers to whether strategy type moderates the effect of high (but no low) monetary compensation through anger on nWOM. Table 1, Panel A (left side) depicts the results for high monetary compensation, indicating a significant positive index of moderated mediation $(\mathrm{b}=.45, \mathrm{SE}=.23, \mathrm{CI}: .01$ to .91$)$. Results indicate a significant negative indirect effect of high monetary compensation on nWOM through anger for a hard termination $(b=-$ $.46, \mathrm{SE}=.15, \mathrm{CI}:-.78$ to -.18$)$, but not for a soft termination $(\mathrm{b}=-.02, \mathrm{SE}=.16, \mathrm{CI}:-.33$ to .30). These results support H3a. Table 1, Panel A (right side) depicts the results for low monetary compensation, indicating the expected null effect. There is no significant index of moderated mediation $(b=.29, \mathrm{SE}=.23, \mathrm{CI}:-.15$ to .75$)$, with non-significant indirect effects both for hard and soft termination.

Test of $H 3 b$. H3b refers to whether strategy type moderates the effect of monetary compensation through anger on image. Table 1, Panel B (left side) depicts the results for high monetary compensation, indicating a significant negative index of moderated mediation $(b=-$ $.45, \mathrm{SE}=.22, \mathrm{CI}:-.89$ to -.01$)$. The indirect effect of high monetary compensation on image through anger is significant and positive for a hard termination strategy $(b=.45, \mathrm{SE}=.15, \mathrm{CI}$ : .17 to .75$)$, but non-significant for a soft strategy $(b=-.02, \mathrm{SE}=.16, \mathrm{CI}:-.29$ to .34$)$. These results support $\mathrm{H} 3 \mathrm{~b}$. Table 1, Panel B (right side) depicts the results for low monetary compensation, indicating a null effect. There is no significant index of moderated mediation (b $=-.28, \mathrm{SE}=.22, \mathrm{CI}:-.72$ to .14$)$, with non-significant indirect effects both for the hard and soft termination strategy.

Table 1 To Be Inserted Here

\section{Discussion}


Study 2 a validates Study 1 findings for high monetary compensation with another sample (consumers) and industry (banking): High, but not low, monetary compensation decreases nWOM and increases corporate image, through reducing anger. Importantly, Study 2a results provide evidence of a conditional processing. High monetary compensation only reduces anger and subsequent nWOM in case of a hard termination strategy, but not in case of a soft strategy. The same mechanism applies to corporate image, which is only increased through anger reduction in case of a hard, not a soft, termination approach. Results indicate termination strategy as a boundary condition: it is ineffective to invest monetary resources on terminated customers if the firm offers to help them find another provider.

\section{Study 2b}

Purpose

Study $2 \mathrm{~b}$ focuses on explanation as the most effective organizational tactic according to Study 1 findings (telecom sector and students). Again, one purpose of Study $2 b$ is to check the robustness of this finding in another context (banking sector and consumers). The main purpose is to test termination strategy (hard vs. soft) as a moderator (H4) on the process "explanation $\rightarrow$ anger $\rightarrow$ nWOM, image". Finally, we include a no termination condition and test if an explanation can put customers on par with a no termination situation, that is, whether nWOM and image reach levels as if the customers were not dismissed.

\section{Design and data collection}

We conducted a scenario-based experiment with a 2 (service termination strategy: hard vs. soft) by 2 (explanation: absent vs. present) between-subject design, yielding four conditions. The baseline scenario described the closure of a bank account (see Online Appendix A 5. for 
scenarios). We also added another group where no termination occurs but the bank communicates neutral information as follows: "Because of the competitive nature of the market, we have decided to review our service offerings. This is in line with the industry norms and current evaluations of the services offered by other banks. We will communicate any changes in due course."

Participants were US adult consumers recruited through an online panel, Clickworker, in exchange for a small compensation. The 180 participants who completed the questionnaire were randomly assigned to the conditions (female: $62.8 \%$, younger than 35 years: $46.1 \%$, married: $44.4 \%$, at least a college degree: $58.9 \%$ ).

\section{Manipulations}

Again, we used video clips and manipulated termination strategy similar to Study 2a. Explanation was manipulated as follows: "Our records indicate that you have been excessively withdrawing money from the non-network ATMs, which is imposing additional charge on us. And while we have clearly explained in the terms and conditions our fair usage policy as a key requirement of our fee-free withdrawal facility, the number of withdrawals you have made during this time has led us to believe that we are unable to meet your current banking needs."

\section{Measures}

Like in Study 2a, the dependent variables were nWOM $(\alpha=.95)$, image $(\alpha=.98)$, and anger $(\alpha=.95)$, and we included the same controls: attitude towards complaining (ATC) $(\alpha=.87)$, severity $(\alpha=.92)$, service importance, attributions $(\alpha=.85)$, as well as gender and age.

Results 
Manipulation check. As an attention check, respondents were asked whether the bank wanted to close their account. $94 \%$ and $96 \%$ of participants correctly responded to the check in the no termination (i.e., understood that their account would not be closed) and termination conditions (i.e., understood that their account would be closed), respectively. Eight respondents with incorrect answers were excluded. The manipulation of explanation was checked with four items from Mostafa et al. (2015) using a 7-point Likert scale (e.g., The bank explained why the problem has happened; $\alpha=.97)$. The mean of the explanation condition was significantly higher than the no explanation condition $\left(\mathrm{M}_{\text {Explanation }}=5.70>\mathrm{M}_{\text {No Explanation }}=1.54, \mathrm{p}<.001\right)$. Respondents perceived the scenarios as realistic (same two items as in previous studies; $\alpha=$ $.91)$, with the mean values significantly higher than the scale midpoint $(M=5.65, t=21.68, p$ $<.001)$ and no differences across groups $(\mathrm{F}=1.49, \mathrm{p}=.21)$. Hence, the manipulations were successful.

ANCOVA results for effects of termination. We first compare the experimental groups with termination conditions against the no termination condition, using two ANCOVAs for nWOM and image. All analyses include the six control variables. Results show a significant effect of termination on $\mathrm{nWOM}\left(\mathrm{F}=12.16, \mathrm{p}<.001, \eta^{2}=.23\right)$ and image $\left(\mathrm{F}=15.27, \mathrm{p}<.001, \eta^{2}=.28\right)$.

For nWOM, post-hoc tests reveal that compared to the no termination group $(\mathrm{M}=3.68)$, service termination without an explanation significantly increases nWOM, both in the hard (M $=5.64, \mathrm{p}<.001)$ and soft strategy conditions $(\mathrm{M}=4.53, \mathrm{p}<.05)$. Importantly, explanation reduces nWOM to a level that does not differ significantly from the no termination group, both in the hard $(\mathrm{M}=3.78, \mathrm{p}=.80)$ and soft strategy conditions $(\mathrm{M}=3.40, \mathrm{p}=.44)$.

For image, post-hoc tests show that compared to the no termination group $(M=4.13)$, service termination without an explanation significantly reduces image in both hard termination $(\mathrm{M}=1.90, \mathrm{p}<.001)$ and soft termination $(\mathrm{M}=3.09, \mathrm{p}<.01)$. Further, explanation improves 
image to an extent that is not significantly different from the no termination group, both in the hard $(4.08, \mathrm{p}=89)$ and soft termination $(4.25, \mathrm{p}=.74)$ conditions.

\section{Hypothesis testing}

We excluded the no termination group $(n=34)$ and tested hypotheses using the PROCESS Model 8 (Hayes, 2013), by comparing the no explanation group with the explanation group.

Test of $\mathrm{H} 4 \mathrm{a}$. H4a refers to whether the effect of explanation through anger on nWOM is moderated by strategy type. Results (see Table 2) show a significant negative indirect effect of explanation on nWOM through anger for both a hard $(\mathrm{b}=-1.48, \mathrm{SE}=.26, \mathrm{CI}:-2.02$ to -.99$)$ and soft termination $(\mathrm{b}=-.93, \mathrm{SE}=.27, \mathrm{CI}:-1.48$ to -.42$)$, but there is no significant difference between the two based on the index of moderated mediation $(\mathrm{b}=.55, \mathrm{SE}=.35, \mathrm{CI}:-.16$ to 1.26). Therefore, H4a is not supported.

Test of $H 4 b . \mathrm{H} 4 \mathrm{~b}$ refers to whether strategy type moderates the effect of explanation through anger on corporate image. Results indicate that the indirect effect of explanation on image through anger is significant and positive for both a hard $(\mathrm{b}=1.48, \mathrm{SE}=.28, \mathrm{CI}: .96$ to 2.06$)$ and soft termination $(\mathrm{b}=.93, \mathrm{SE}=.27, \mathrm{CI}: .41$ to 1.47$)$. However, the index of moderated mediation does not show any significant difference between the two termination strategies (b $=-.55, \mathrm{SE}=.36, \mathrm{CI}:-1.28$ to .12 ). Hence, $\mathrm{H} 4 \mathrm{~b}$ is not supported.

Table 2 To Be Inserted Here

\section{Discussion}


Study $2 \mathrm{~b}$ reveals that service termination (both hard and soft strategy) significantly increases nWOM and reduces image compared with a no termination condition, but offering explanation can offset these negative consequences and put customers' nWOM, image, and anger levels on par with a no service termination situation. Additionally, Study $2 b$ validates Study 1 findings for explanation with another sample (consumers) and industry (banking): Following both hard and soft termination, explanation is effective in decreasing nWOM and increasing corporate image, through reducing anger levels. However, there is no significant difference between the two termination strategies with regards to the indirect effects of explanation on nWOM and image. Hence, unlike monetary compensation, offering an explanation is always an effective firm tactic to influence customers' reactions in service termination.

\section{General discussion and theoretical implications}

Previous studies have shown that termination of customer relationships triggers customers' anger and nWOM (Mittal et al., 2008), damages firm's image (Alajoutsijärvi et al., 2000), and reduces other existing customers' loyalty intentions and prospective customers' desire to join the company (Haenlein \& Kaplan, 2010). Yet, only Lepthien et al. (2017) address the effectiveness of monetary compensation and downgrading the customer following contract termination among affected customers. But to the best of our knowledge, no research has analyzed the effectiveness of explanation as a form of psychological compensation, nor has it examined the interaction between organizational tactics and termination strategies to reduce the negative consequences of a service termination. In addition, our knowledge of the mechanism that drives the effectiveness of organizational tactics to service termination is limited. Therefore, this paper makes important contributions to the service termination literature by examining the effectiveness of different organizational tactics and unveiling their boundary conditions. 
Effectiveness of monetary compensation and boundary condition. Only high (but not low) monetary compensation can reduce the undesirability of service termination through mitigating customers' anger, which subsequently reduces nWOM and increases image perceptions. This finding challenges the notion that offering some monetary compensation is better than none (Davidow, 2003; Gelbrich, Gäthke, \& Grégoire, 2016). We also address the call for research by Grewal et al. (2008) in determining the limitations of monetary compensation as a seemingly powerful organizational tactic and as a key remedy for service termination (Lepthien et al., 2017). As a core contribution above Lepthien et al. (2017), we show that high monetary compensation is only effective with a hard termination, but it is rendered unnecessary with a soft approach, when firms help customers move to an alternative provider. This finding is important as it can be directly influenced by the firm.

Effectiveness of explanation and boundary condition. Our most important contribution is examining the effectiveness of explanation. We show that this organizational tactic can reduce firm-agency by shifting the responsibility away from the firm, and it is even more powerful than monetary redress, at least with respect to nWOM. We also demonstrate that its effect is independent of the termination strategy, while monetary compensation only works with hard termination. Interestingly, offering an explanation can fully offset the negative consequences of termination and put customers' nWOM, image, and anger levels on par with a no service termination situation. These findings oppose common knowledge on the effectiveness of different organizational tactics following firms' transgressions. Prior research shows that monetary compensation is the most important remedy (Orsingher, Valentini, \& de Angelis, 2010) and explanation is, at best, "an adequate substitute" (Gelbrich, 2010, p. 580). This is important because explanation is a cost-free alternative to monetary compensation. 
Further, apology, which is considered the core tool for psychological redress in the service failure literature, does not help with an intentional act like customer dismissal. This is consisetent with the finding of Roschk and Kaiser (2013) showing the importance of perceived sincerity of an apology in order to be effective. Deliberately rejecting a customer and-in the same breath—apologizing for this intentional act can be perceived as insincere.

Mediating role of anger. Another contribution is shedding light on the mechanism that drives customers' reactions to service termination and organizational tactics. We address the call for research by Haenlein and Kaplan (2012) on the role of customers' emotional reactions to termination. We draw on cognitive appraisal theory to show how firm-initiated service termination as an undesirable, controllable, and intentional act (i.e., clear firm-attribution) can elicit anger (Watson \& Spence, 2007) and subsequently trigger negative behavioral reactions (Frijda et al., 1989). Previously, Lepthien et al. (2017) adopted justice as the anchor to explain customers' reactions to service termination. However, our study enhances our understanding of service termination by demonstrating the diminishing effects of justice and a key role that anger plays in explaining the effectiveness of organizational tactics on customers' reactions to service termination. This is because, unlike justice, anger captures the firm-agency comprising controllability and intentionality entailed in service termination. Accordingly, anger is considered to be the primary predictor of negative behavioral reactions, thus relativizing the role of justice (Beijersbergen et al., 2015), particularly in a termination context.

\section{Managerial implications}

We provide managerial recommendations on how to reduce the negative consequences of service termination. As a top priority, managers should explain why they terminated the relationship. Offering a truthful explanation, regardless of the termination strategy, can diffuse 
customers' anger through helping them see the problem from the firm's perspective and reevaluating their blame attribution. In fact, a good explanation can fully eliminate customers' negative reactions to termination. Yet, this is in sharp contrast with firms' current practices, according to customer complaints filed with the US Consumer Financial Protection Bureau (CFPB, 2016), which is referring customers to the terms and conditions (i.e., stating that firms have the right to unilaterally end the relationship) or refusing to provide any information at all (e.g., by redirecting customers' calls to an automated voice mail).

These practices seem to further fuel customers' negative emotions. Given that anger plays a major role in driving customers' reactions to termination, service managers can be more creative and use different tactics to manage customer anger. For example, service termination often comes as a shock (Haenlein and Kaplan, 2010), but Mittal et al. (2008) suggest that prior warning may reduce customers' negative reactions. This is because, advance warning may partly shift the blame from the firm, by passing more responsibility for the situation to customers, which can ultimatey reduce anger. In addition, it is important to provide training for service employees to ensure they acquire the skills needed when dealing with angry customers (Bougie et al. , 2003). Particularly, acknowleding terminated customers' anger before responding to their complaints may already reduce blamefulness before implementing any other tactic. Employees could, for example, use empathetic words such as "I understand that this may come as a disappointment, but let me explain why we believe another provider may be more suitable for you."

Although providing an explanation for service termination is the most desirable tactic, some firms may refrain from offering an explanation in fear of being sued due to discriminatory behavior (Haenlein \& Kaplan, 2009). Here, in lieu of explanation, [high] monetary compensation (as the next best tactic) can help reduce the damages caused by a hard termination. In this regard, it is crucial for managers to know how much remuneration should 
be offered to dismissed customers. This study offers an initial indication of low $(£ 50 / \$ 100)$ and high (£150/\$200) level of monetary compensation following service termination based on two different industries and countries. We propose that firms should follow an "all-or-nothing" approach for financial remuneration, and termination strategy plays a key role here. Firms that follow a hard strategy need to provide high financial redress to compensate for the economic loss comprised in service termination ("all"). In contrast, firms following a soft strategy, which is helping customers with a smooth transition to another provider, should not offer any monetary remuneration ("nothing").

Our reseach also allows recommendations on when to choose the hard termination with high compensation or soft termination with no compensation approach. The former strategy should be chosen by firms lacking the willingness, ability, or capacity to help customers find an alternative provider. This hard approach may comprise low effort at first glance, but leads to higher negative consequences which requires a high monetary compensation. Hence, firms are well advised to pursue a soft approach if they have a profound market knowledge along with a good network and thus, are able to find alternative providers at low search costs. Alternative providers could be subsidiaries, strategic partners in a network (Mittal et al., 2008), or even competing firms with business models that are more appropriate for their dismissed customers (Rosenblum, Tomlinson, \& Scott, 2003). In choosing a soft termination strategy, firms can "kill two birds with one stone": save money that is otherwise needed for compensation and reduce the negative consequences of service termination.

Ultimately, there is a general trade-off for firms how to spend their resources to minimize the negative consequences of termination. Firms can either offer monetary compensation to terminated customers (to reduce nWOM and improve image) or alternatively avoid paying financial compensation to affected customers (risking nWOM and lower sales), but rather offer reduced prices or better quality to attract potential customers. Our research 
helps settle this trade-off by showing that firms can save the costs of monetary compensation either through explaining the reason for termination or helping customers move to an alternative provider. However, if firms refrain from an explanation or a soft termination (e.g., for strategic reasons), they may need to invest money into compensation for affected customers, rather than into price reductions for customer acquistion. This is because the nWOM from the affected customers can spread through social media, making it easier than ever for the public and potential customers to find out about firm's transgressions (such as customer termination). According to Haenlein and Kaplan (2010), when potential customers find out about such practices, price reductions to attract these potential customers are ineffective.

\section{Limitations and future research}

Some limitations of our studies provide opportunities for future research. First, we have an initial indication of the low and high level of compensation for service termination. However, these values may be country- and context-specific. Therefore, it is important to replicate the studies in different countries and industries. Second, given that many customers often have more than one service with a financial institution (e.g., current account, savings account, and home insurance), future research can investigate whether termination of one service offering can lead customers' to voluntary switching to other providers (i.e., cutting all ties with that firm). Third, one could examine customers' reactions to different reasons for termination (e.g., customer misbehaviour vs. lack of profitability or firms aiming to maximize profit). Finally, in our experiments, the termination and explanation scenarios were aimed at individuals rather than a group of customers and the explanation which was offered to the individual proved to be effective. But, future researchers should examine the moderating effect of the size of termination (i.e., single vs. group termination) as suggested by Albrecht, Walsh, and Beatty 
(2016) and the effectiveness of using different communication styles (e.g., one to one vs. one to many communication) as suggested by Vaerenbergh, Larivière, and Vermeir (2012).

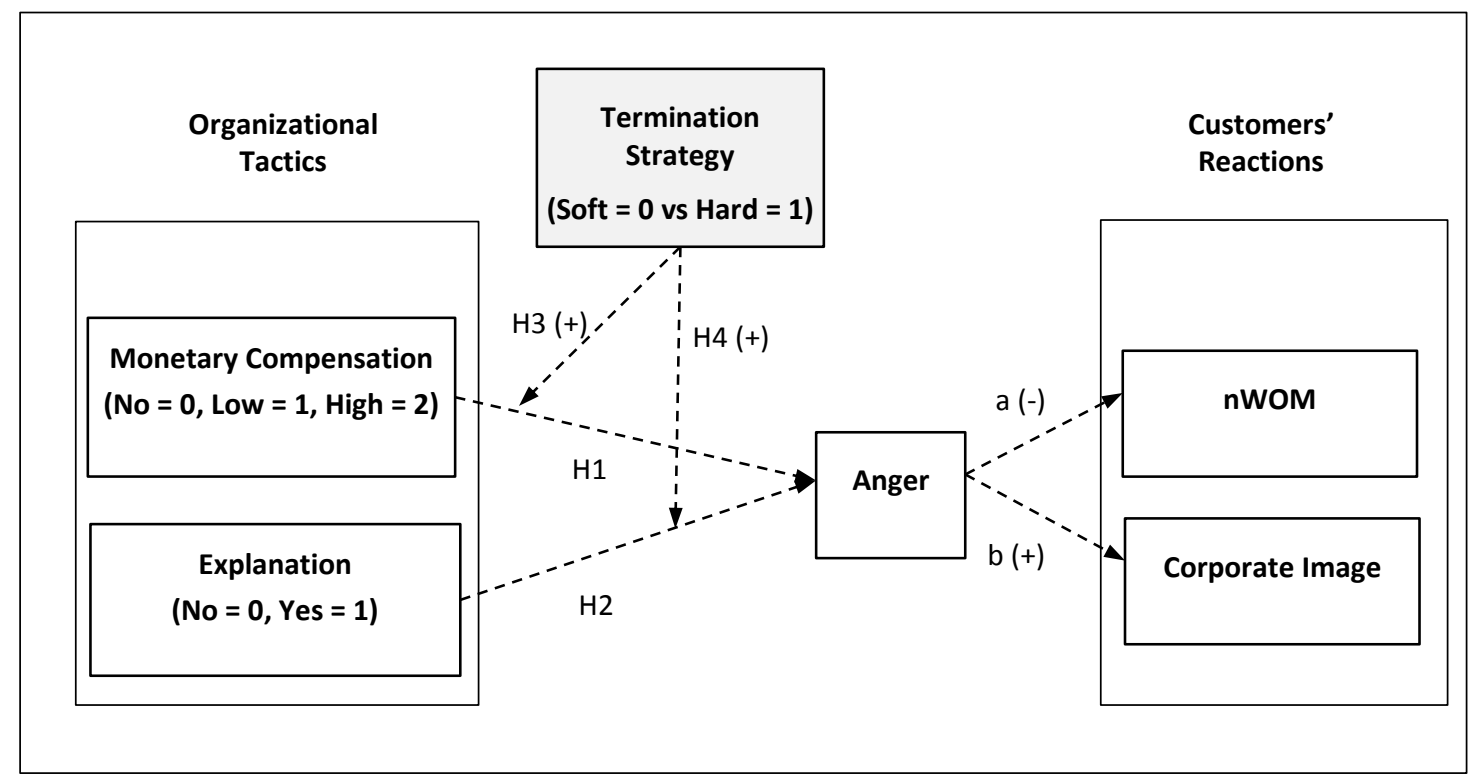

Figure 1. Conceptual framework 


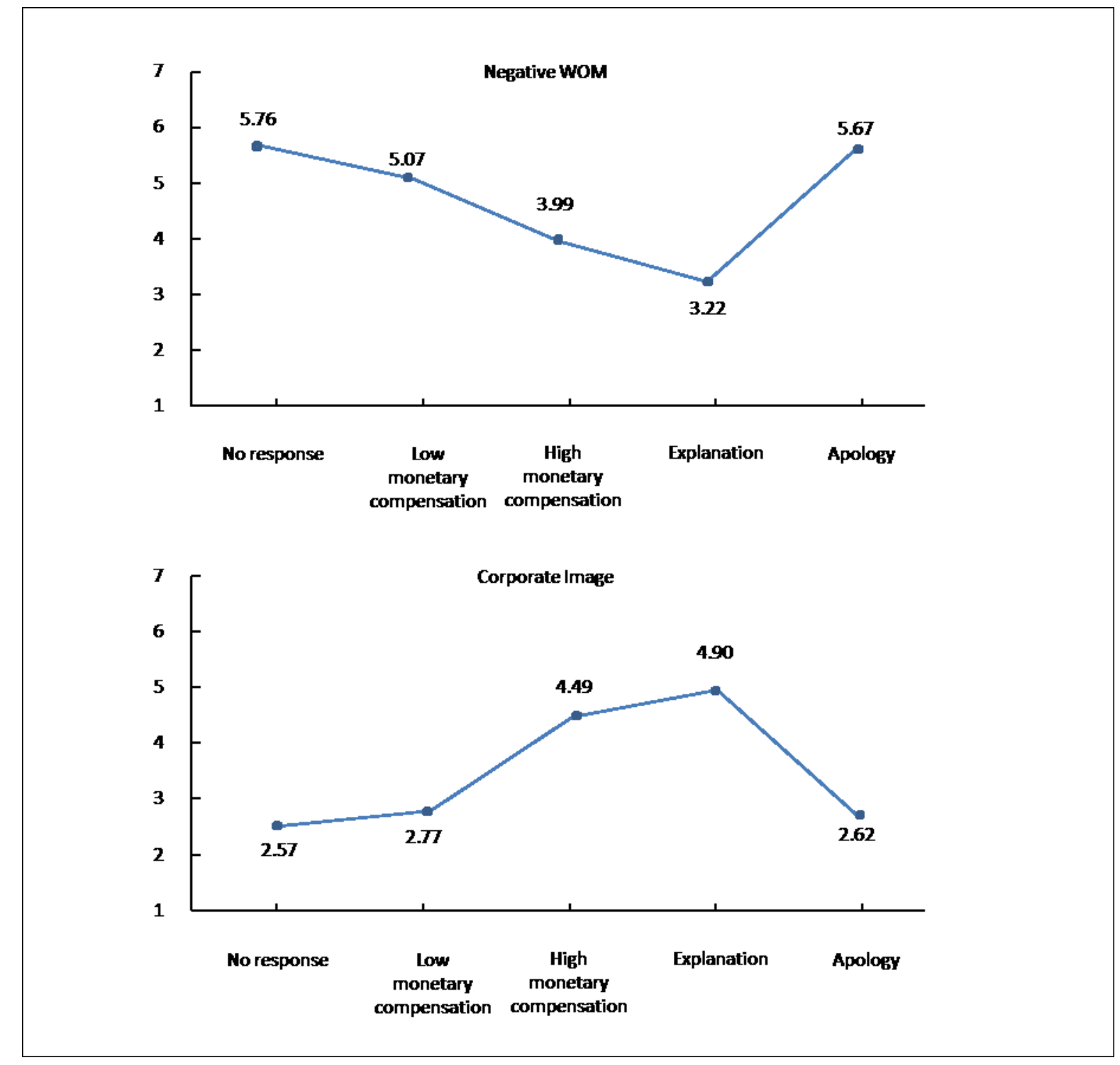

Figure 2. Mean values of nWOM and image for experimental groups (Study 1). 
Table 1. Results of moderated mediation analysis (Study 2a).

\begin{tabular}{|c|c|c|c|c|c|c|c|}
\hline Panel A: Results for nWOM & & & & & & & \\
\hline \multirow[t]{3}{*}{ High monetary compensation } & \multicolumn{7}{|c|}{ Low monetary compensation } \\
\hline & $\mathbf{b}$ & SE & $95 \% \mathrm{Cl}$ & Index of moderated mediation & b & SE & $95 \% \mathrm{Cl}$ \\
\hline & .45 & .23 & {$[.01 ; .91]$} & & .29 & .23 & {$[-.15 ; .75]$} \\
\hline Indirect effects & b & SE & $95 \% \mathrm{Cl}$ & Indirect effects & b & SE & $95 \% \mathrm{Cl}$ \\
\hline Hard termination strategy & -.46 & .15 & {$[-.78 ;-.18]$} & Hard termination strategy & -.27 & .14 & {$[-.56 ; .00]$} \\
\hline Soft termination strategy & -.02 & .16 & {$[-.33 ; .30]$} & Soft termination strategy & .02 & .17 & {$[-.32 ; .35]$} \\
\hline
\end{tabular}

Panel A: Results for corporate image

\begin{tabular}{|c|c|c|c|c|c|c|c|}
\hline High monetary compensation & & & & rate monetary compensation & & & \\
\hline \multirow[t]{2}{*}{ Index of moderated mediation } & b & SE & $95 \% \mathrm{Cl}$ & Index of moderated mediation & b & SE & $95 \% \mathrm{Cl}$ \\
\hline & -.45 & .22 & $-.89 ;-.01$ & & -.28 & .22 & {$[-.72 ; .14]$} \\
\hline Indirect effects & b & SE & $95 \% \mathrm{Cl}$ & Indirect effects & b & SE & $95 \% \mathrm{Cl}$ \\
\hline Hard termination strategy & .45 & .15 & {$[.17 ; .75]$} & Hard termination strategy & .26 & .14 & {$[-.00 ; .54]$} \\
\hline Soft termination strategy & -.02 & .16 & {$[-.29 ; .34]$} & Soft termination strategy & -.02 & .17 & {$[-.35 ; .31]$} \\
\hline
\end{tabular}


Table 2. Results of moderated mediation analysis (Study 2b).

\begin{tabular}{|c|c|c|c|c|c|c|c|}
\hline nWOM & & & & Image & & & \\
\hline \multirow[t]{2}{*}{ Index of moderated mediation } & b & SE & $95 \% \mathrm{Cl}$ & Index of moderated mediation & b & SE & $95 \% \mathrm{Cl}$ \\
\hline & .55 & .35 & {$[-16 ; 1.26]$} & & -.55 & .36 & {$[-1.28 ; .12]$} \\
\hline Indirect effects & b & SE & $95 \% \mathrm{Cl}$ & Indirect effects & b & SE & $95 \% \mathrm{Cl}$ \\
\hline Hard termination strategy & -1.48 & .26 & {$[-2.02 ;-.99]$} & Hard termination strategy & 1.48 & .28 & {$[.96 ; 2.06]$} \\
\hline Soft termination strategy & -.93 & .27 & {$[-1.48 ;-.42]$} & Soft termination strategy & .93 & .27 & {$[-41 ; 1.47]$} \\
\hline
\end{tabular}




\section{References}

Alajoutsijärvi, K., Möller, K., \& Tähtinen, J. (2000). Beautiful exit: how to leave your business partner. European Journal of Marketing, 34(11/12), 1270-1290.

Albrecht, A. K., Walsh, G., \& Beatty, S. E. (2016). Perceptions of Group Versus Individual Service Failures and Their Effects on Customer Outcomes: The Role of Attributions and Customer Entitlement. Journal of service research, 20(2), 188-203.

Averill, J. R. (1983). Studies on anger and aggression: implications for theories of emotion. American psychologist, 38(11), 1145.

Bagozzi, R. P. (1975). Marketing as exchange. The Journal of Marketing, 32-39.

Balaji, M., \& Sarkar, A. (2013). Does successful recovery mitigate failure severity? A study of the behavioral outcomes in Indian context. International Journal of Emerging Markets, 8(1), 6581.

Bambauer-Sachse, S., \& Rabeson, L. (2015). Determining adequate tangible compensation in service recovery processes for developed and developing countries: The role of severity and responsibility. Journal of Retailing and Consumer Services, 22, 117-127.

Bateson, J. E., \& Hui, M. K. (1992). The ecological validity of photographic slides and videotapes in simulating the service setting. Journal of consumer research, 19(2), 271-281.

Beijersbergen, K. A., Dirkzwager, A. J., Eichelsheim, V. I., Van der Laan, P. H., \& Nieuwbeerta, P. (2015). Procedural justice, anger, and prisoners' misconduct: A longitudinal study. Criminal Justice and Behavior, 42(2), 196-218.

Benoit, W. L., \& Drew, S. (1997). Appropriateness and effectiveness of image repair strategies. Communication Reports, 10(2), 153-163.

Bougie, R., Pieters, R., \& Zeelenberg, M. (2003). Angry customers don't come back, they get back: the experience and behavioral implications of anger and dissatisfaction in services. Journal of the Academy of Marketing science, 31(4), 377-393.

CFPB. (2016). Data \& Research | Consumer Financial Protection Bureau. Retrieved from http://www.consumerfinance.gov/data-research/

Chebat, J.-C., Davidow, M., \& Codjovi, I. (2005). Silent voices why some dissatisfied consumers fail to complain. Journal of service research, 7(4), 328-342.

Chebat, J.-C., \& Slusarczyk, W. (2005). How emotions mediate the effects of perceived justice on loyalty in service recovery situations: an empirical study. Journal of Business Research, 58(5), 664-673.

Colquitt, J. A. (2001). On the dimensionality of organizational justice: a construct validation of a measure. Journal of applied psychology, 86(3), 386-400.

Coombs, W. T., \& Holladay, S. J. (2008). Comparing apology to equivalent crisis response strategies: Clarifying apology's role and value in crisis communication. Public Relations Review, 34(3), 252-257.

Dave, P. (2014). Bank clients of Middle Eastern descent want answers on closed accounts. Los Angeles Times. Retrieved from http://www.latimes.com/nation/la-na-banks-muslims-20140907story.html

Davidow, M. (2003). Organizational responses to customer complaints: What works and what doesn't. Journal of service research, 5(3), 225-250.

De Cremer, D., Wubben, M. J., \& Brebels, L. (2008). When Unfair Treatment Leads to Anger: The Effects of Other People's Emotions and Ambiguous Unfair Procedures 1. Journal of Applied Social Psychology, 38(10), 2518-2549.

Fournier, S., Breazeale, M., \& Fetscherin, M. (2012). Consumer-brand Relationships: Theory and Practice. Abingdon, Oxon: Routledge.

Freiberger, H. (2017). Too poor for the bank [Online]. Süddeutsche Zeitung. 03 August 2017. Retrieved from http://www.sueddeutsche.de/wirtschaft/donner-reuschel-zu-arm-fuer-die-bank1.3615031 
Frijda, N. H., Kuipers, P., \& Ter Schure, E. (1989). Relations among emotion, appraisal, and emotional action readiness. Journal of Personality and Social Psychology, 57(2), 212.

Gelbrich, K. (2010). Anger, frustration, and helplessness after service failure: coping strategies and effective informational support. Journal of the Academy of Marketing science, 38(5), 567-585.

Gelbrich, K., Gäthke, J., \& Grégoire, Y. (2015). How Much Compensation Should a Firm Offer for a Flawed Service? An Examination of the Nonlinear Effects of Compensation on Satisfaction. Journal of service research, 18(1), 107-123.

Gelbrich, K., Gäthke, J., \& Grégoire, Y. (2016). How a firm's best versus normal customers react to compensation after a service failure. Journal of Business Research, 69(10), 4331-4339.

Grégoire, Y., \& Fisher, R. J. (2008). Customer betrayal and retaliation: when your best customers become your worst enemies. Journal of the Academy of Marketing science, 36(2), 247-261.

Grégoire, Y., Laufer, D., \& Tripp, T. M. (2010). A comprehensive model of customer direct and indirect revenge: understanding the effects of perceived greed and customer power. Journal of the Academy of Marketing science, 38(6), 738-758.

Grewal, D., Roggeveen, A. L., \& Tsiros, M. (2008). The effect of compensation on repurchase intentions in service recovery. Journal of Retailing, 84(4), 424-434.

Haenlein, M., \& Kaplan, A. M. (2009). Unprofitable customers and their management. Business Horizons, 52(1), 89-97.

Haenlein, M., \& Kaplan, A. M. (2010). An Empirical Analysis of Attitudinal and Behavioral Reactions Toward the Abandonment of Unprofitable Customer Relationships. Journal of Relationship Marketing, 9(4), 200-228.

Haenlein, M., \& Kaplan, A. M. (2011). Evaluating the consequences of abandoning unprofitable customers: a comparison of direct and indirect abandonment strategies. Zeitschrift fuer Betriebswirtschaft, 81(2), 77-94.

Haenlein, M., \& Kaplan, A. M. (2012). The impact of unprofitable customer abandonment on current customers' exit, voice, and loyalty intentions: an empirical analysis. Journal of Services Marketing, 26(6), 458-470.

Haenlein, M., Kaplan, A. M., \& Schoder, D. (2006). Valuing the real option of abandoning unprofitable customers when calculating customer lifetime value. Journal of marketing, 70(3), 5-20.

Hayes, A. F. (2013). Introduction to mediation, moderation, and conditional process analysis: A regression-based approach. New York: Guilford Press.

Hayes, A. F., \& Preacher, K. J. (2014). Statistical mediation analysis with a multicategorical independent variable. British Journal of Mathematical and Statistical Psychology, 67(3), 451-470.

Hess, R. L., Ganesan, S., \& Klein, N. M. (2003). Service failure and recovery: the impact of relationship factors on customer satisfaction. Journal of the Academy of Marketing science, 31(2), 127145.

Kotler, P., \& Levy, S. J. (1971). Demarketing, yes, demarketing. Harvard Business Review, 49(6), 74-80.

Lazarus, R., S. (1991). Emotion and adaptation. New York: Oxford.

Lepthien, A., Papies, D., Clement, M., \& Melnyk, V. (2017). The ugly side of customer managementConsumer reactions to firm-initiated contract terminations. International Journal of Research in marketing, 34(4), 829-850.

Mattila, A. S. (2001). The effectiveness of service recovery in a multi-industry setting. Journal of Services Marketing, 15(7), 583-596.

Mikula, G., Scherer, K. R., \& Athenstaedt, U. (1998). The role of injustice in the elicitation of differential emotional reactions. Personality and social psychology bulletin, 24(7), 769-783.

Mittal, V., Sarkees, M., \& Murshed, F. (2008). The right way to manage unprofitable customers. Harvard Business Review, 86(4), 94-103.

Mostafa, R. B., Lages, C. R., Shabbir, H. A., \& Thwaites, D. (2015). Corporate Image A Service Recovery Perspective. Journal of service research, 18(4), 468-483.

Murphy, K., \& Tyler, T. (2008). Procedural justice and compliance behaviour: The mediating role of emotions. European journal of social psychology, 38(4), 652-668. 
Nguyen, D. T., \& McColl-Kennedy, J. R. (2003). Diffusing customer anger in service recovery: A conceptual framework. Australasian Marketing Journal (AMJ), 11(2), 46-55.

Orsingher, C., Valentini, S., \& de Angelis, M. (2010). A meta-analysis of satisfaction with complaint handling in services. Journal of the Academy of Marketing science, 38(2), 169-186.

Ortony, A., \& Clore, G. (1988). A. collins (1988). The cognitive structure of emotions.

Perdue, B. C., \& Summers, J. O. (1986). Checking the success of manipulations in marketing experiments. Journal of marketing research, 317-326.

Roggeveen, A. L., Tsiros, M., \& Grewal, D. (2012). Understanding the co-creation effect: when does collaborating with customers provide a lift to service recovery? Journal of the Academy of Marketing science, 40(6), 771-790.

Roschk, H., \& Gelbrich, K. (2014). Identifying Appropriate Compensation Types for Service Failures A Meta-Analytic and Experimental Analysis. Journal of service research, 17(2), 195-211.

Roschk, H., \& Kaiser, S. (2013). The nature of an apology: An experimental study on how to apologize after a service failure. Marketing Letters, 24(3), 293-309.

Rosenblum, D., Tomlinson, D., \& Scott, L. (2003). Bottom-feeding for blockbuster businesses. Harvard Business Review, 81(3), 52-59, 139.

Ruth, J. A., Brunel, F. F., \& Otnes, C. C. (2002). Linking thoughts to feelings: Investigating cognitive appraisals and consumption emotions in a mixed-emotions context. Journal of the Academy of Marketing science, 30(1), 44-58.

Shaw, J. C., Wild, E., \& Colquitt, J. A. (2003). To justify or excuse?: A meta-analytic review of the effects of explanations. Journal of applied psychology, 88(3), 444-458.

Smith, A. K., Bolton, R. N., \& Wagner, J. (1999). A model of customer satisfaction with service encounters involving failure and recovery. Journal of marketing research, 356-372.

Tripp, T. M., Bies, R. J., \& Aquino, K. (2007). A vigilante model of justice: Revenge, reconciliation, forgiveness, and avoidance. Social Justice Research, 20(1), 10-34.

Van Vaerenbergh, Y., Larivière, B., \& Vermeir, I. (2012). The Impact of Process Recovery Communication on Customer Satisfaction, Repurchase Intentions, and Word-of-Mouth Intentions. Journal of service research, 15(3), 262-279.

Varela-Neira, C., Vázquez-Casielles, R., \& Iglesias, V. (2014). Intentionality attributions and humiliation: The impact on customer behavior. European Journal of Marketing, 48(5/6), 901-923.

Walster, E., Berscheid, E., \& Walster, G. W. (1973). New directions in equity research. Journal of Personality and Social Psychology, 25(2), 151-176.

Wang, C.-y., \& Mattila, A. S. (2011). A cross-cultural comparison of perceived informational fairness with service failure explanations. Journal of Services Marketing, 25(6), 429-439.

Watson, L., \& Spence, M. T. (2007). Causes and consequences of emotions on consumer behaviour: A review and integrative cognitive appraisal theory. European Journal of Marketing, 41(5/6), 487-511.

Weber, H. (2004). Explorations in the social construction of anger. Motivation and Emotion, 28(2), 197-219. 